\title{
On the Combined Application of Iatroscan TLC-FID and GC-FID to Identify Total, Neutral, and Polar Lipids and Their Fatty Acids Extracted from Foods
}

\author{
Vassilia J. Sinanoglou, ${ }^{1}$ Irini F. Strati, ${ }^{1}$ Sotirios M. Bratakos, ${ }^{1}$ Charalampos Proestos, ${ }^{2}$ \\ Panagiotis Zoumpoulakis, ${ }^{3}$ and Sofia Miniadis-Meimaroglou ${ }^{2}$ \\ ${ }^{1}$ Instrumental Food Analysis Laboratory, Department of Food Technology, Technological Educational Institute of Athens, \\ Ag. Spyridonos, 12210 Egaleo, Greece \\ ${ }^{2}$ Food Chemistry Laboratory, Department of Chemistry, University of Athens, Panepistimioupolis Zographou, 15701 Athens, Greece \\ ${ }^{3}$ Institute of Biology, Medicinal Chemistry \& Biotechnology, National Hellenic Research Foundation, \\ Vas. Constantinou Avenue, 11636 Athens, Greece \\ Correspondence should be addressed to Vassilia J. Sinanoglou; v_sinanoglou@yahoo.gr
}

Received 22 November 2012; Accepted 11 December 2012

Academic Editors: F. Couderc, B. Fernandez De Simon, and H. M. Rawel

Copyright ( 2013 Vassilia J. Sinanoglou et al. This is an open access article distributed under the Creative Commons Attribution License, which permits unrestricted use, distribution, and reproduction in any medium, provided the original work is properly cited.

An efficient separation and quantification of the individual neutral and polar lipid classes and their constituent fatty acids was achieved by the combination of two different detection techniques: Iatroscan TLC-FID and GC-FID. The solvent composition and ratio of development system, the sample size, the fidelity, and precision were tested in order to estimate the effectiveness of separation of individual neutral and polar lipid classes and the quantitative reproducibility of the Iatroscan TLC-FID technique. GC-FID method, with a high-quality capillary column, allowed sensitive and reproducible fatty acid qualitative and quantitative analyses, separation of fatty acid structural isomers (e.g., n-C16:0, iso-C16:0 and anteiso-C16:0), positional isomers (e.g., C18:1 $\omega-9$ and C18:1 $\omega$-7), geometrical isomers (cis-trans), and homologues (e.g., C16:0, C17:0, C18:0, etc.) in standards and complex lipid samples. Seventeen (17) lipid classes and fifty-two (52) saturated (SFA), monounsaturated (MUFA), and polyunsaturated (PUFA) fatty acids were identified and quantified, respectively, in samples of standard lipid and fatty acid mixtures, simulating the composition of natural lipids and their fatty acid methyl esters in common foods. The wide number of applications establishes this combination of Iatroscan TLC-FID and GC-FID methods as a powerful tool for lipid class and fatty acid analysis of any fat origin.

\section{Introduction}

Fat and fatty acids especially polyunsaturated ones contribute to important aspects of fish, meat, and plant products' quality and are critical for their nutritional and sensory value. Therefore, it is required to improve methods for the separation of total lipids into their neutral and polar fractions and for the analysis of their fatty acids (FA). Neutral lipid FA composition of animal and marine fat is strongly associated with their diet, whereas polar lipids regulate the function of membrane cells.
Iatroscan is an instrument that combines thin-layer chromatography (TLC) resolution efficacy with the capacity of quantification by flame ionization detection (FID) $[1,2]$. Neutral and polar lipids (e.g., triglycerides, sterols, phospholipids) cannot be separated by gas chromatography (GC) or high-performance liquid chromatography (HPLC) without fractionation, saponification, derivatization, or other pretreatment methods [3] and HPLC also requires availability of suitable columns for analysis of different polarity lipid. On the other hand, TLC/FID is adaptable and flexible as the separation can be achieved by adjusting polarity of solvent system 
without changing the stationary phase. Besides, Iatroscan is able to analyze 30 samples in $2-3 \mathrm{hr}$, a rate that cannot be matched by GC or HPLC [4].

The purposes of this work were (a) to study the suitability of the Iatroscan TLC-FID analysis for rapid and complete separation and quantitation of neutral lipids (NL) into individual NL classes as well as polar lipids (PL) into individual phospholipid ( $\mathrm{PhL}$ ) classes; (b) to improve the separation capacity of GC-FID analysis of saturated and unsaturated fatty acid methyl esters (FAME) due to the nutritional and health benefits of fatty acids, especially the $\omega-3$ and $\omega-6$ ones. Finally this study was designed to improve the suitability of the combined use of Iatroscan TLC-FID and GC-FID for lipid analysis. Moreover, this combination is examined and proposed as a method of choice for complete qualitative and quantitative analysis of food lipids and their constituents' fatty acids.

\section{Materials and Methods}

2.1. Standards and Solvents. The lipid standards used were cholesteryl oleate, cholesterol, octadecyl hexadecanoate, squalene, tristearoyl-glycerol, stearic acid, oleic acid, 1,3distearoyl-glycerol, 1,2-distearoyl-glycerol, 1-monostearoylrac-glycerol, phosphatidylcholine, phosphatidylethanolamine, lysophosphatidylcholine, lysophosphatidylethanolamine, phosphatidylinositol, phosphatidylserine, and sphingomyeline standards of the Sigma Chemical Co (Sigma-Aldrich Company, Dorset, Great Britain and St. Louis, MO, USA) as well as egg yolk and mollusc muscle lipids available by our laboratory (Instrumental Food Analysis Laboratory, Department of Food Technology).

Fatty acid methyl esters standards with chain lengths from C4 to C24 from two sources were used: (a) authentic standard mixtures commercially available (Supelco 37 Component FAME Mix C4-C24, 100 mg Neat. Catalog No.: 189191AMP and Supelco PUFA No. 1, Marine Source, $100 \mathrm{mg}$ Neat. Catalog No. 47033. Fatty acid methyl ester standards ( $5 \mathrm{mg}$ of each) from Sigma Chemical Co: palmitic acid M$\mathrm{E}$; stearic acid M-E, oleic acid (cis-9) M-E, linoleic acid (cis-9,12) M-E and cis-5,8,11,14,17-eicosapentaenoic acid ME (MIDI Inc.; Supelco; Lordano; Sigma-Aldrich), and (b) FAME gained from egg yolk, mollusc muscle, and lamb meat lipids available by our laboratory. All solvents used for sample preparation were of analytical grade and the solvents used for GC and Iatroscan TLC-FID analyses were of HPLC grade from Merck (Darmstadt, Germany). Double-distilled water was used throughout this work. All reagents used were of analytical grade and were purchased from Mallinckrodt Chemical Works (St. Louis, MO, USA) and from Sigma Chemical Co (Sigma-Aldrich Company, UK).

2.2. Iatroscan Analysis of Neutral and Polar Lipids. Lipid classes were separated on silicic acid-coated quartz rods, chromarods (Type SIII) (5 mm silica gel-coated quartz rod, Iatron Labs, Tokyo, Japan), and afterwards they were quantified using a thin layer chromatography-flame ionisation detection system. TLC-FID analysis was performed by an
Iatroscan thin-layer chromatograph (Model MK-6 TLC/FIDFPD Analyser Iatron Laboratories, Tokyo, Japan) equipped with a flame ionization detector and connected to a personal computer for collecting the chromatograms. Operation conditions for the Iatroscan were $160 \mathrm{~mL} \mathrm{~min}{ }^{-1}$ hydrogen flow, $2 \mathrm{~L} \mathrm{~min}^{-1}$ air flow, and $30 \mathrm{~s} /$ chromarod scan speed [5]. Chromarods were activated by passing them through the FID scanner immediately before sample spotting and $1 \mu \mathrm{L}$ of the sample solution was applied on each rod. A $1 \mu \mathrm{L}$ Hamilton syringe (Hamilton Co., Reno, NV, USA) was used to spot standards and samples. The rods were developed $10 \mathrm{~cm}$ from the origin in a lined chromatography tank with a one- or twosolvent system. To obtain a good vapour saturation of the development tank, a filter paper was erected along one side of the bath and wetted with solvent system. Each bath was prepared $30 \mathrm{~min}$ before development. The temperature of the room is maintained at $22^{\circ} \mathrm{C}$. After developing, the chromarod holder (10 chromarods) was dried in a desiccator for a few minutes and then immediately each chromarod was scanned with the FID to detect and quantify the compounds separated on silica. Chromstar 6.3 Software was used to calculate peak areas and retention times.

\subsection{Gas Chromatography Analysis of Fatty Acid Methyl Esters.} Fatty acid methyl esters (FAME) of total lipids were prepared according to the procedure described by Sinanoglou and Miniadis-Meimaroglou [6]. Both quantitative and qualitative analyses were performed on an Agilent 6890 Series Gas Chromatograph (Agilent Technologies, Palo Alto, CA, USA) equipped with a flame ionization detector. DB23 capillary column $(60 \mathrm{~m} \times 0.25 \mathrm{~mm}$ i.d. $0.15 \mu \mathrm{m}$ film $)$ [50\%-Cyanopropyl-methylpolysiloxane] (Agilent Technologies. Catalogue No.: 122-2361) was used. The analysis was split injection. Helium was used as a carrier gas. The injector and detector temperatures were $250^{\circ} \mathrm{C}$ and $260^{\circ} \mathrm{C}$, respectively. The temperature was programmed at $100^{\circ} \mathrm{C}$ for $0 \mathrm{~min}$, raised from 100 to $150^{\circ} \mathrm{C}$ by a rate of $10^{\circ} \mathrm{C} \mathrm{min}{ }^{-1}$, and held constant at $150^{\circ} \mathrm{C}$ for $0 \mathrm{~min}$. Then it raised from 150 to $195^{\circ} \mathrm{C}$ by a rate of $2^{\circ} \mathrm{C} \mathrm{min}{ }^{-1}$ and held constant at $195^{\circ} \mathrm{C}$ for $5 \mathrm{~min}$. Then it raised from 195 to $210^{\circ} \mathrm{C}$ by a rate of $1^{\circ} \mathrm{C} \mathrm{min}$ min $^{-1}$ and held constant at $210^{\circ} \mathrm{C}$ for $0 \mathrm{~min}$ and finally raised from 210 to $240^{\circ} \mathrm{C}$ by a rate of $10^{\circ} \mathrm{C} \mathrm{min} \mathrm{m}^{-1}$ and held constant at $240^{\circ} \mathrm{C}$ for $5 \mathrm{~min}$. The duration of the analysis was altogether $55.50 \mathrm{~min}$. The injection volumes were $1.0 \mu \mathrm{L}$. Hewlett-Packard Chem Station Software was used to calculate peak areas and retention times.

2.4. Statistical Analysis. All measurements were obtained (at least) in triplicate and values were averaged and reported along with the standard deviation (S.D). All data concerning lipid and fatty acid composition were analyzed with OneWay ANOVA Post Hoc Tests and pairwise multiple comparisons were conducted with the Tukey's honestly significant difference test. Possibilities less than 0.05 were considered statistically significant $(P<0.05)$. All statistical calculations were performed with the SPSS (IBM SPSS Statistics, version 19) statistical software for Windows. 


\section{Results and Discussion}

3.1. Separation of Neutral and Polar Lipids by Iatroscan. The present study focuses on introducing a procedure for the efficient separation and quantification of the individual neutral and polar lipid classes. Several solvent systems consisting of n-hexane, diethyl ether, petroleum ether, chloroform, methanol, acetone, formic acid, acetic acid, ammonia, and water were tested with lipid standards and egg yolk lipids in order to achieve their efficient separation. Solvent systems consisting of $\mathrm{n}$-hexane-diethyl ether gave better separation of neutral from polar lipid classes than those of n-hexane-petroleum ether. Chloroform-methanol combination gave better phospholipids separation than chloroformacetone. The presence of acetone causes the development of carotenoids associated with the phospholipids. Formic and acetic acid addition in neutral solvent systems gave better separation of triglycerides and free fatty acids than ammonia. Formic acid was preferable than acetic acid since it was more volatile and thus easily removed from the rods prior to scanning. Thus, the neutral and polar solvent systems chosen were hexane-diethyl ether with or without formic acid system combinations (HDF) and chloroform : methanol : water : with or without formic acid (CMWF) solvent system combinations, respectively.

The neutral solvent systems further examined consisted of $\mathrm{n}$-hexane-diethyl ether-formic acid (n-H:DE:FA) [42: $28: 0.3,55: 20: 1.5,60: 15: 1.5,62.6: 6.6: 0.8,65: 5: 0.15$, $66.5: 3.5: 1.7$, and $54.9: 3.7: 1.4]$ (by vol.) as well as of $n$ hexane-diethyl ether (n-H:DE) [72:0.8 by vol.]. The presence of formic acid was found necessary in order to avoid broadening peaks. Wax ester appeared as a small peak just before sterol ester but it was incompletely separated, when present in large amount, in all the solvent system tested. The most effective separation of TG from FFA as well as of diacylglycerol isomers 1,2 and 1,3 from free sterols was achieved when a solvent system of $n-H: D E: F A$ was used, with the ratio of $\mathrm{n}-\mathrm{H}: \mathrm{DE}$ exceeding $4: 1$. Thus, n$\mathrm{H}$ : DE : FA ( $60: 15: 1.5$ by vol.) (solvent A) was selected as the most appropriate solvent system for individual neutral lipid separation. A typical separation of neutral lipid standards using the Iatroscan and the above-mentioned solvent system designed to separate neutral lipids is shown in Figure 1(a). The retention times of the separated standards are shown in Table 1.

Different ratios in chloroform : methanol: water solvent system, conventionally used in TLC for the separation of polar lipids, were tested. The examined polar solvent systems consisted of chloroform:methanol:water (C:M:W) [45.2:22.6:2.2; $50: 25: 2.5 ; 45: 20: 2$ (2 times); $45: 20: 2$ (1 time); $48: 22: 1 ; \quad 50: 20: 2.5 ; \quad 50: 20: 2 ; \quad 50: 20: 2.5$ $(5 \mathrm{~cm})$ and $60: 10: 1(10 \mathrm{~cm})]$ (by vol.) as well as of chloroform: methanol: water: formic acid (C:M:W:FA) [ $45: 25: 2.5: 1$ and $45: 20: 2: 1$ ] (by vol). The best separations for phospholipids were obtained with $C: M: W(50: 20: 2$, $45: 20: 2$ and $48: 22: 1$, by vol.), while the best separation between PI and PS was obtained with C:M:W $(50: 20: 2$, by vol.). L-PE appeared as a small peak just after PS but it was incompletely separated, when present in large amounts.

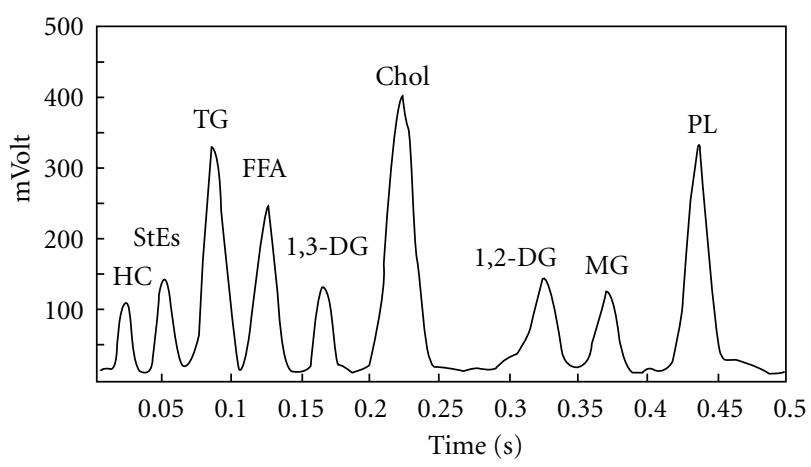

(a)

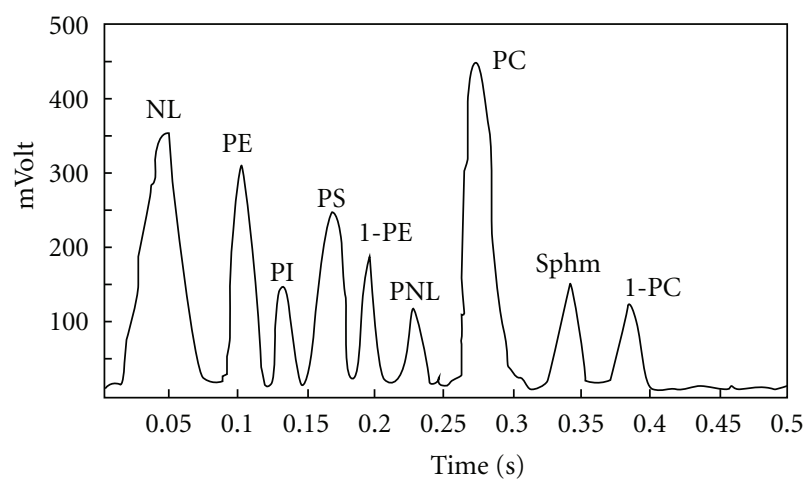

(b)

Figure 1: Chromatograms of (a) standard neutral lipids developed with $\mathrm{n}$-hexane-diethyl ether-formic acid $(60: 15: 1.5$ by vol.), (b) standard phospholipids developed with chloroform : methanol: water $(50: 20: 2$ by vol. $)$.

As natural lipid samples contain trace amount of 1-PE this peak could be easily separated from PS peak. In the same solvent system ceramide aminoethylphosphonic acid (phosphonolipid) appeared as a small peak between PS and PC when mollusc muscle lipid sample was applied in chromarods, in accordance to the findings of Sinanoglou and Miniadis-Meimaroglou [7]. Therefore, the solvent system selected for the separation of phospholipid standards was $\mathrm{C}: \mathrm{M}: \mathrm{W}(50: 20: 2$, by vol.) (solvent $\mathrm{B}$ ). The chromatogram of standard phospholipids developed by the above-mentioned solvent system is shown in Figure 1(b). The retention times of the separated standards are tabulated in Table 1.

Various multiple development solvent systems were examined, consisting of $\mathrm{C}: \mathrm{M}: \mathrm{W}$ (first development) and $\mathrm{n}-\mathrm{H}: \mathrm{DE}: \mathrm{FA}$ (second development) $[50: 20: 2.5(5 \mathrm{~cm})$ and $65: 5: 0.15(10 \mathrm{~cm})$ by vol], [ $50: 20: 2.5(6 \mathrm{~cm})$ and $65: 5: 0.15$ $(10 \mathrm{~cm})$ by vol], $[50: 20: 2.5(7 \mathrm{~cm})$ and $65: 5: 0.15(10 \mathrm{~cm})$ by vol], [50:20:2 (5cm) and $65: 5: 0.15(10 \mathrm{~cm})$ by vol], $[50: 20: 2(5 \mathrm{~cm})$ and $60: 15: 0.15(10 \mathrm{~cm})$ by vol], and [ $45: 20: 2(5 \mathrm{~cm})$ and $60: 15: 0.15(10 \mathrm{~cm})$ by vol]. The overlap of $\mathrm{MG}$ and $\mathrm{PE}$ peaks did not allow the quantification of these two classes of compounds when their amount was higher than $0.2 \mu \mathrm{g}$ on the chromarod. In order to achieve better separation, the polarity of the first elution 
TABLE 1: Retention time, calibration data, and reproducibility for neutral and polar lipid standards.

\begin{tabular}{|c|c|c|c|c|c|c|}
\hline Solvent system & Lipid standards & $\begin{array}{c}\text { Retention } \\
\text { time }\end{array}$ & $\begin{array}{c}\text { Regression } \\
\text { equation }\end{array}$ & $\begin{array}{c}\text { Correlation } \\
\text { coefficients }\left(r^{2}\right)\end{array}$ & $\begin{array}{c}\text { CV\% of intraday } \\
\text { variability }\end{array}$ & $\begin{array}{c}\mathrm{CV} \% \text { of interday } \\
\text { variability }\end{array}$ \\
\hline \multirow{9}{*}{$\begin{array}{l}\text { Solvent A } \\
\text { (n-H : DE : FA) } \\
(60: 15: 1.5 \text { by vol. })\end{array}$} & $\mathrm{HC}$ & $0.02-0.03$ & $y=124.3 x+10.2$ & 0.9994 & 1.28 & 1.69 \\
\hline & $\begin{array}{l}\text { Sterol esters } \\
\text { (wax esters) }\end{array}$ & $0.04-0.06$ & $y=178.4 x-2.7$ & 1 & 1.34 & 1.76 \\
\hline & TG & $0.07-0.10$ & $y=253.45 x+17.7$ & 0.9984 & 2.33 & 1.83 \\
\hline & FFA & $0.11-0.12$ & $y=157.7 x+68$ & 0.9926 & 1.57 & 2.21 \\
\hline & $1,3-\mathrm{DG}$ & $0.16-0.18$ & $y=136.5 x+6.1$ & 0.9987 & 1.62 & 2.49 \\
\hline & Sterol & $0.20-0.24$ & $y=301.3 x-5$ & 1 & 2.28 & 3.46 \\
\hline & $1,2-\mathrm{DG}$ & $0.31-0.34$ & $y=149.2 x+4.4$ & 1 & 1.29 & 1.87 \\
\hline & MG & $0.36-0.39$ & $y=126.9 x-3.2$ & 0.9993 & 1.56 & 2.17 \\
\hline & $\mathrm{PL}$ & $0.42-0.45$ & - & - & - & - \\
\hline \multirow{9}{*}{$\begin{array}{l}\text { Solvent B } \\
(\mathrm{C}: \mathrm{M}: \mathrm{W}) \\
(50: 20: 2 \text {, by vol. })\end{array}$} & NL & $0.02-0.08$ & - & - & - & - \\
\hline & $\mathrm{PE}$ & $0.09-0.11$ & $y=201.35 x+6.3$ & 0.9987 & 1.74 & 2.86 \\
\hline & PI & $0.11-0.14$ & $y=205.11 x-5.6$ & 0.9997 & 2.64 & 3.35 \\
\hline & PS & $0.15-0.18$ & $y=136.8 x+3.9$ & 0.9997 & 2.47 & 3.68 \\
\hline & 1-PE & $0.19-0.20$ & $y=158.2 x+4.1$ & 0.9995 & 1.92 & 3.04 \\
\hline & $\mathrm{PnL}$ & $0.21-0.23$ & - & - & - & - \\
\hline & PC & $0.24-0.30$ & $y=277.4 x+14$ & 0.9997 & 1.40 & 2.48 \\
\hline & Sphm & $0.33-0.35$ & $y=190.5 x+1$ & 0.9994 & 1.76 & 2.55 \\
\hline & 1-PC & $0.37-0.40$ & $y=137.23 x+3.4$ & 0.9998 & 1.63 & 2.26 \\
\hline
\end{tabular}

Development distance/times of development: $10 \mathrm{~cm}$ (1 time).

system was increased, by decreasing the ratio of chloroform. Thus, $\mathrm{C}: \mathrm{M}: \mathrm{W}$ (first development) and $\mathrm{n}-\mathrm{H}: \mathrm{DE}: \mathrm{FA}$ (second development) $[45: 20: 2(5 \mathrm{~cm})$ and $60: 15: 0.15(10 \mathrm{~cm})$ by $\mathrm{vol}$ ] were selected as the most appropriate solvent systems for $\mathrm{NL}$ and PL separation in the same Iatroscan chromatogram.

Based on the results obtained, the quantification of individual neutral and polar lipid classes was achieved using calibration curves obtained for each authentic standard by plotting peak area against lipid concentration (different concentrations: $0.5,1.0,2.0,4.0,6.0,8.0,10.0,15.0$, and $20.0 \mu \mathrm{g}$ $\mu \mathrm{L}^{-1}$ per standard lipid) under the same chromatogram and development conditions (solvent $\mathrm{A}$ and $\mathrm{B}$, resp.). The FTD response of neutral and polar fractions versus the lipid amount spotted could be expressed as linear or nonlinear regression. Different models were tested and, finally, the linear curve $y=a+b x$ was chosen for both neutral and polar fractions, where $y$ is the peak area and $x$ is the lipid amount $(\mu \mathrm{g})$ spotted on the rod. Linear regression curve offers the advantages of good fitting and simplicity for further calculations in order to determine the quantity of lipid components. All correlation coefficients for standard lipids calibration curves were higher than $0.9926\left(r^{2}=0.9926\right.$ to 1.0000 ) (Table 1). Four concentrations of $0.01,0.02,0.05$, and $0.1 \mu \mathrm{g} \mu \mathrm{L}^{-1}$ for each lipid standard were prepared and spotted to chromarods. The detection limit (DL) were calculated based on signal-to-noise $(\mathrm{S} / \mathrm{N}) \leq 3$ and quantitation limit (QL) based on $\mathrm{S} / \mathrm{N} \leq 10$. DL was found $0.02 \mu \mathrm{g} \mu \mathrm{L}^{-1}$ and $\mathrm{QL}$ $0.05 \mu \mathrm{g} \mu \mathrm{L}^{-1}$ per lipid standard, respectively.
The reproducibility of the measurement was performed from the analysis of two pure standard mixtures of neutral and polar lipids in appropriate ratios simulating the lipid composition of most food samples. Therefore, a composite standard for neutral lipids using squalene, cholesteryl oleate, tristearoyl-glycerol, cholesterol, oleic acid, 1,3-distearoyl-glycerol 1,2-distearoyl-glycerol, and 1 -monostearoyl-rac-glycerol, in the ratios $1 / 1 / 5 / 3 / 1 / 1 / 1 / 1$ by $\mathrm{wt}$, as well as for the polar lipids using phosphatidylcholine, phosphatidylethanolamine, lyso-phosphatidylcholine, lysophosphatidylethanolamine, phosphatidylinositol, phosphatidylserine, and sphingomyeline in the ratios $4 / 2 / 1 / 1 / 1 / 1 / 1$ by wt, was prepared. Reproducibility was tested by spotting the same standard mixture on 10 chromarods and measuring the standard deviation (SD) and the coefficient of variation (CV\%). The neutral solvent system consisted of $\mathrm{n}-\mathrm{H}$ : DE : FA $(60: 15: 1.5$ by vol.) while the polar solvent system consisted of $\mathrm{C}: \mathrm{M}: \mathrm{W}(50: 20: 2$. by vol.). Four series of ten rods were analysed over a three-day period per mixture selecting a total lipid concentration $\leq 20.0 \mu \mathrm{g} \mu \mathrm{L}^{-1}$. The results of coefficient of variation $(\mathrm{CV} \%)$ of the intra-day variability and the inter-day variability for the lipid standards (Table 1) proved that the reproducibility of the method was satisfactory for analytical validation purposes [8].

The above separation of NL and PL by Iatroscan TLCFID offers several advantages over TLC. Higher sensitivity and better recovery were obtained, particularly for lipids present in very small amounts. TLC-FID has the additional advantage to run mixture of lipid standards in separate 


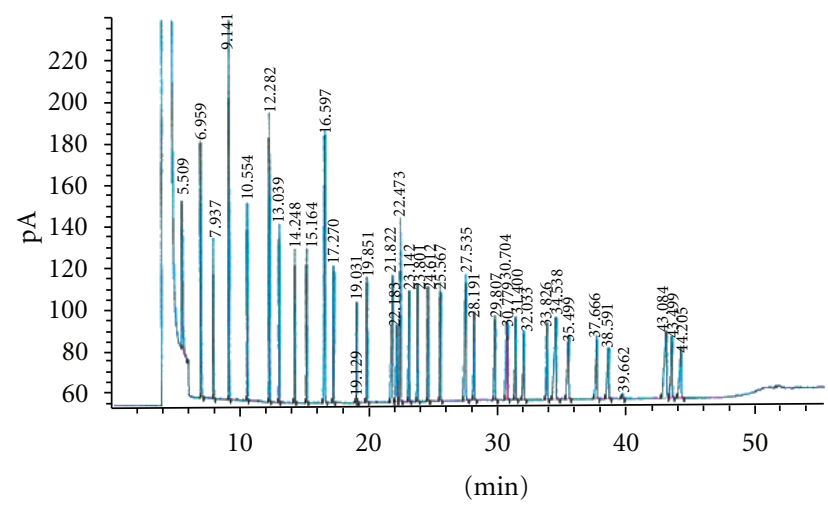

FIGURE 2: Typical chromatogram showing the separation of FAME standards Supelco 37 Component FAME Mix C4-C24, (Merck, Darmstadt, Germany) on a DB-23 capillary column $(60 \mathrm{~m} \times$ $0.25 \mathrm{~mm}$ i.d. $0.15 \mu \mathrm{m}$ film). Chromatographic conditions: split injection (split ratio $1: 2$ ).

chromarod to check separation in each analysis. The neutral and polar lipid separation in individual NL and $\mathrm{PhL}$ classes is completed in a reasonable time of approximately 1 and $0.5 \mathrm{~h}$, respectively, per 10 analyses. Complex lipid samples do not require pretreatment and even a small sample size (few $\mu \mathrm{g})$ is sufficient for analysis. Seventeen lipid classes (HC, TG, FFA, Sterols, Wax esters, Sterol Esters, 1,2-DG, 1,3-DG, MG, PE, 1-PE, PI, PS, PnL, PC, 1-PC and Sphm) were identified in samples of standard lipid mixtures.

3.2. Identification and Quantification of Fatty Acid Methyl Esters by Modified GC-FID. The procedure for fatty acid methyl esters (FAME) analysis using the GC conditions as modified in this study and described in the Material and Methods paragraph, was applied to commercially FAME standards. Figure 2 presents a GC chromatogram of the reference standard mixture. Fatty acids were identified by comparing the retention times of FAME with the Supelco 37 Component FAME Mix, Supelco PUFA No.1, Marine Source (Table 2). FAMEs not included in these standards were compared with the peaks of well-recognized samples, that is, egg yolk, mollusc, and crustacean total lipid fatty acids from previous studies realised by the same research team and under similar conditions [9-12]. According to the results of Table 2, FAME retention time (RT) is influenced by stationary phase polarity, column length, temperature program, fatty acid molecule chain length, unsaturation degree, and isomerisation and chromatographic conditions, as expected. Fifty-two (52) saturated (SFA), monounsaturated (MUFA) and polyunsaturated (PUFA) fatty acids were identified and quantified. The temperature program selected was a tradeoff between the resolution of fatty acid structural isomers (e.g., $\mathrm{n}-\mathrm{C} 16: 0$, iso-C16:0, and anteiso-C16:0) or positional isomers

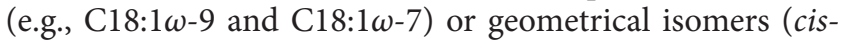
trans) or homologues (e.g., C16:0, C17:0, and C18:0) and the maximum elution time. Therefore, the temperature program used, although long, was considered appropriate for FAME separation and quantification even for complex fat samples.
TABLE 2: FAME retention times and response factors.

\begin{tabular}{|c|c|c|c|}
\hline $\mathrm{A} / \mathrm{A}$ & FAME & Rt (min) & $\mathrm{Rf}$ (split ratio1:2) \\
\hline 1 & C4:0 & $4.200-4.405$ & $0.37369 \pm 0.00613$ \\
\hline 2 & C6:0 & $4.580-4.760$ & $0.37436 \pm 0.00628$ \\
\hline 3 & $\mathrm{C} 8: 0$ & $5.438-5.808$ & $0.38637 \pm 0.00043$ \\
\hline 4 & $\mathrm{C} 10: 0$ & $6.897-7.158$ & $0.35074 \pm 0.00134$ \\
\hline 5 & C10:1 & $7.325-7.579$ & $0.35074 \pm 0.00134$ \\
\hline 6 & C11:0 & $7.877-8.088$ & $0.34422 \pm 0.00189$ \\
\hline 7 & C12:0 & $9.064-9.251$ & $0.33555 \pm 0.00149$ \\
\hline 8 & C13:0 & $10.484-10.641$ & $0.32852 \pm 0.00054$ \\
\hline 9 & C14:0 & $12.168-12.398$ & $0.32561 \pm 0.00068$ \\
\hline 10 & C14:1 & $12.954-13.131$ & $0.32998 \pm 0.00015$ \\
\hline 11 & Iso-C15:0 & $13.556-13.685$ & $0.33183 \pm 0.00018$ \\
\hline 12 & Anteiso-C15:0 & $13.782-13.956$ & $0.33183 \pm 0.00018$ \\
\hline 13 & C15:0 & $14.148-14.354$ & $0.33183 \pm 0.00018$ \\
\hline 14 & C15:1 $\omega-5$ & $15.064-15.274$ & $0.32497 \pm 0.00054$ \\
\hline 15 & C16:0 & $16.400-16.791$ & $0.32226 \pm 0.00096$ \\
\hline 16 & Iso-C16:0 & $16.978-17.162$ & $0.32226 \pm 0.00096$ \\
\hline 17 & C16:1 $\omega-9$ (cis) & $17.212-17.394$ & $0.32717 \pm 0.00102$ \\
\hline 18 & Iso-C $17: 0$ & $18.465-18.588$ & $0.41283 \pm 0.00352$ \\
\hline 19 & Anteiso-C17:0 & $18.612-18.688$ & $0.41283 \pm 0.00352$ \\
\hline 20 & Cyclo-C17:0 & $18.705-18.855$ & $0.41283 \pm 0.00352$ \\
\hline 21 & $\mathrm{C} 17: 0$ & $18.948-19.100$ & $0.41283 \pm 0.00352$ \\
\hline 22 & $\mathrm{C} 17: 1 \omega-7$ & $19.728-19.994$ & $0.31718 \pm 0.00197$ \\
\hline 23 & C18:0 & $21,573-22,000$ & $0.33312 \pm 0.00352$ \\
\hline 24 & C18:1 $\omega-9$ trans & $22.000-22.285$ & $0.32846 \pm 0.00342$ \\
\hline 25 & $\mathrm{C} 18: 1 \omega-9$ cis & $22.285-22.668$ & $0.32299 \pm 0.00323$ \\
\hline 26 & $\mathrm{C} 18: 1 \omega-7$ cis & $22.749-22.909$ & $0.32299 \pm 0.00323$ \\
\hline 27 & C18:2 $\omega-6$ cla & $23.011-23.301$ & $0.32597 \pm 0.00337$ \\
\hline 28 & $\mathrm{C} 18: 2 \omega-6 \mathrm{t} 9, \mathrm{t} 11$ & $23.314-23.301$ & $0.32597 \pm 0.00337$ \\
\hline 29 & $\mathrm{C} 18: 2 \omega-6$ cis & $23.671-23.951$ & $0.32122 \pm 0.00311$ \\
\hline 30 & $\mathrm{C} 18: 3 \omega-6$ cis & $24.488-24.764$ & $0.32818 \pm 0.00318$ \\
\hline 31 & $\mathrm{C} 18: 3 \omega-3$ cis & $25.434-25.721$ & $0.29582 \pm 0.00282$ \\
\hline 32 & $\mathrm{C} 18: 4 \omega-3$ cis & $26.305-26.515$ & $0.29582 \pm 0.00282$ \\
\hline 33 & C19:0 & $27.336-27.492$ & $0.34611 \pm 0.00491$ \\
\hline 34 & C20:0 & $27.492-27.653$ & $0.34611 \pm 0.00491$ \\
\hline 35 & $\mathrm{C} 20: 1 \omega-9$ cis & $28.042-28.485$ & $0.33910 \pm 0.00490$ \\
\hline 36 & $\mathrm{C} 20: 2 \omega-6$ cis & $29.660-29.867$ & $0.32028 \pm 0.00444$ \\
\hline 37 & C20:3 $\omega-6$ cis & $30.528-30.660$ & $0.33346 \pm 0.00356$ \\
\hline 38 & $\mathrm{C} 20: 4 \omega-6$ cis & $31.235-31.508$ & $0.34295 \pm 0.00620$ \\
\hline 39 & $\mathrm{C} 20: 3 \omega-3$ cis & $31.888-32.037$ & $0.33598 \pm 0.00527$ \\
\hline 40 & $\mathrm{C} 21: 0$ & $32.964-33.282$ & $0.37696 \pm 0.00544$ \\
\hline 41 & $\mathrm{C} 20: 5 \omega-3$ cis & $33.675-34.151$ & $0.33962 \pm 0.00476$ \\
\hline 42 & C22:0 & $34.329-34.598$ & $0.36969 \pm 0.00904$ \\
\hline 43 & $\mathrm{C} 22: 1 \omega-9$ cis & $36.285-36.361$ & $0.34866 \pm 0.00589$ \\
\hline 44 & $\mathrm{C} 22: 1 \omega-11$ cis & $36.534-36.892$ & $0.34866 \pm 0.00589$ \\
\hline 45 & $\mathrm{C} 22: 2 \omega-6$ cis & $37.633-37.753$ & $0.34738 \pm 0.00604$ \\
\hline 46 & C23:0 & $37.979-38.308$ & $0.38454 \pm 0.00781$ \\
\hline 47 & $\mathrm{C} 22: 4 \omega-6$ cis & $38.527-38.743$ & $0.34295 \pm 0.00620$ \\
\hline 48 & $\mathrm{C} 22: 5 \omega-6$ cis & $39.855-40.198$ & $0.34295 \pm 0.00620$ \\
\hline 49 & $\mathrm{C} 22: 5 \omega-3$ cis & $40.386-40.822$ & $0.34295 \pm 0.00620$ \\
\hline 50 & C24:0 & $42.544-42.703$ & $0.40016 \pm 0.00753$ \\
\hline 51 & $\mathrm{C} 22: 6 \omega-3$ cis & $43.255-44.162$ & $0.34295 \pm 0.00620$ \\
\hline 52 & $\mathrm{C} 24: 1 \omega-9$ cis & $44.162-44.392$ & $0.35047 \pm 0.00748$ \\
\hline
\end{tabular}




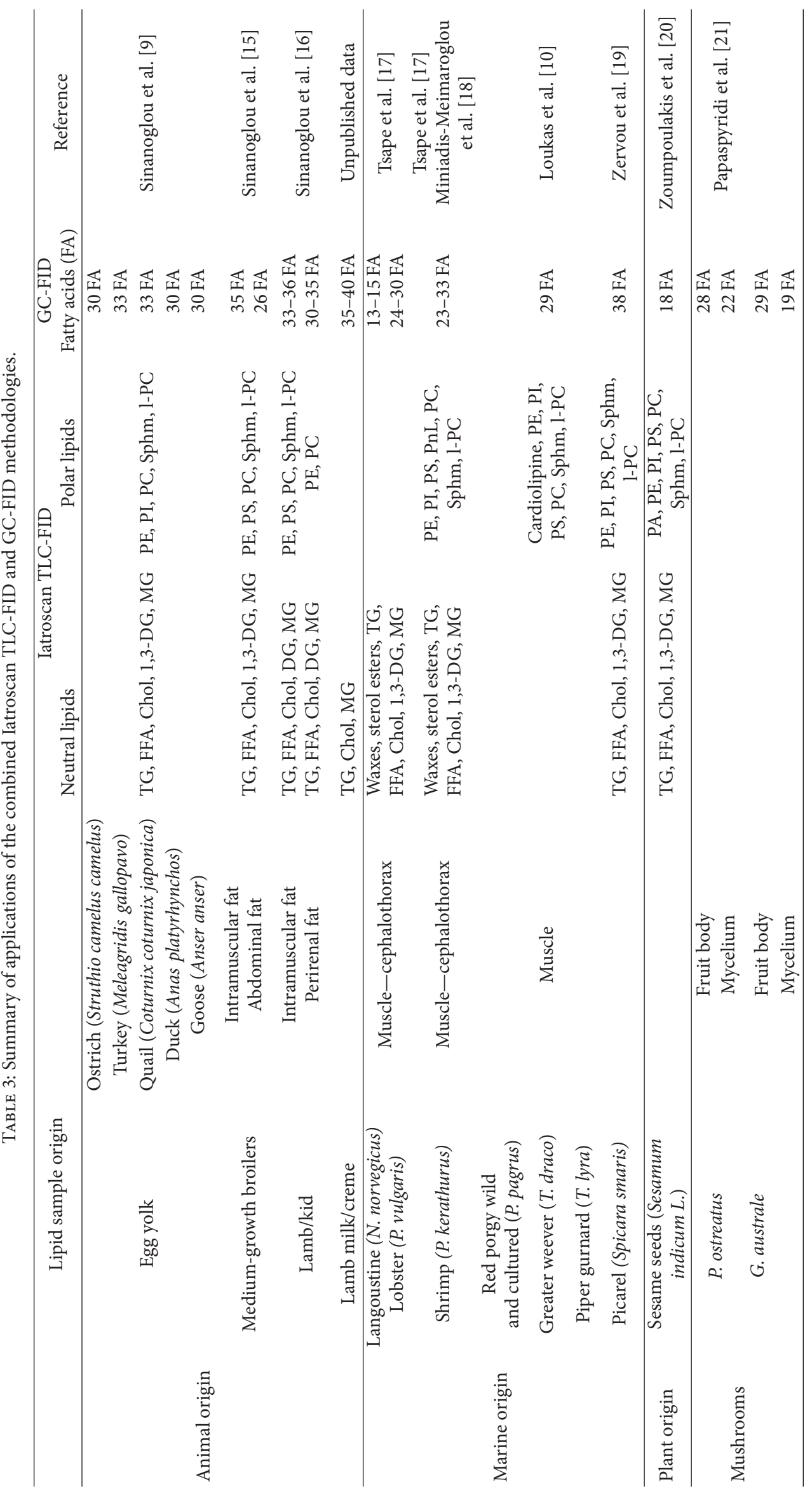


In order to validate the method in terms of linearity, standard solutions containing different concentrations of 37 Component FAME Mix were prepared and subjected to GC analysis. Injection of solutions containing ten different concentrations of 37 Component FAME Mix in n-hexane (ranging from 0.5 to 5.0, from 5.0 to 20.0, and from 10.0 to $30.0 \mu \mathrm{g} \mu \mathrm{L}^{-1}$ for split ratios $1: 2,1: 20$, and $1: 50$, resp.) served to calibrate the system with regard to the different response obtained with each FAME. Chromatographs showed that discrimination ability and analytical sensitivity decreased with the increase of split ratio. Higher split ratio improved peak shape but it had the risk of the loss of ingredients in trace amounts. Since the total lipid content is determined before the analysis, low split ratios were selected. The standard curves for individual FAME were obtained by plotting concentration ratio against area ratio and the correlation coefficient $\left(r^{2}\right)$ was calculated with the linear equations used for quantitation. FAME response factors (Rfs) were then determined according to the FAME standards chromatograms and calculated by the following equation:

$$
\operatorname{Rf}_{\mathrm{FAME}}=\frac{m \text { FAME }(\mu \mathrm{g})}{\text { FAME peak area }\left(\mathrm{cm}^{2}\right)} .
$$

The amounts of FAME in the studied samples were then calculated via the individual FAME peak area and the Rf.

FAME response factors (Rfs) for split ratio $1: 2$ are presented in Table 2.

Dodds et al. [13] demonstrated that FID response factors for different FAME are not equal, a fact confirmed by the analysis of the standards. For FAME identified from known fat samples without corresponding standards, Rf was obtained from their structural or positional isomer or homologue with equal or similar chain length. Individual FAME Rfs remained constant regardless of split ratio since the same integrator events were selected.

The detection limit (DL) and quantitation limit (QL) were obtained for a signal-to-noise $(\mathrm{S} / \mathrm{N})$ ratio of 3 and 10 , respectively. Four concentrations of $0.001,0.002,0.005$, and $0.01 \mu \mathrm{g} \mu \mathrm{L}^{-1}$ in $\mathrm{n}$-hexane for palmitic acid M-E, stearic acid M-E, oleic acid (cis-9) M-E, linoleic acid (cis-9,12) M-E, and cis-5,8,11,14,17-eicosapentaenoic acid M-E were prepared and subjected to GC analysis. Standard deviations were $\leq 0.01$ for all of the analytes. DL was found to be $0.001 \mu \mathrm{g} \mu \mathrm{L}^{-1}$ and QL $0.002 \mu \mathrm{g} \mu \mathrm{L}^{-1}$ per fatty acid methylester, respectively.

Three different concentrations of 37 Component FAME Mix $\left(10.0,15.0\right.$, and $20.0 \mu \mathrm{g} \mu \mathrm{L}^{-1}$ in $\mathrm{n}$-hexane) were used to assess precision. Each sample was run three times within a single day to evaluate repeatability. Reproducibility was evaluated by repeating these analyses on three different days. From the results obtained standard deviations was $\leq 0.01 \%$ and the coefficient of variation (CV\%) of the intraday variability and the inter-day variability for the fatty acid methyl ester standards were $\leq 1.0 \%$ in all cases. The instrumental parameters on the integrator were appropriate to the peak widths at various times during analysis.

The above separation of FAME by GC-FID offers several advantages, such as high repeatability and reproducibility of retention times and high precision in quantitation based on peak area measurements. Several research studies confirmed the stationary phase polarity and column length impact to the resolution of fatty acids isomers [14]. The results of the study showed that the selection of a capillary column with appropriate length resulted in the best separation of FAME isomers.

3.3. Application. The combination of Iatroscan TLC-FID and GC-FID methodologies has been applied to several food samples to identify neutral and polar lipid profiles, composition and fatty acid content of total fat extracted. A summary of these applications is presented in Table 3. The advantages of Iatroscan TLC-FID and GC-FID implementation in lipid and fatty acid analysis were important. Specifically for Iatroscan TLC-FID analysis, the solvent systems and the chromatographic conditions proposed gave satisfactory separation for the lipid classes regardless of the fat origin and the fatty acid constituents of glycerolipids. Diacylglycerol isomers 1,2 and 1,3 were separated from each other, as well as, from free sterols in standards and food samples. Total lipids development in the neutral solvent system A (n-H:DE:FA $60: 15: 1.5$ by vol.), when scanned by the Iatroscan FID, provided polar and neutral lipid proportions. The reproducibility of the method was satisfactory for all standards and fat samples examined.

Besides, for GC-FID analysis, the efficiency of the selected column and temperature programme for separation of the C18 fatty acids and their cis/trans isomers was satisfactory. The method was very useful for the analysis of a wide variety of saturated and unsaturated fatty acid profiles in complex fat mixtures with different compositions. Finally the method provided the profile analysis of individual FAME, expressed as percent of total FAME and the quantitative analysis of individual FAME expressed as w/w of total lipids of food, a factor which is of particular importance when determining the nutritional value of fatty foods.

\section{Conflict of Interests}

The authors declare no conflict of interests.

\section{References}

[1] N. C. Shantha, "Thin-layer chromatography-flame ionization detection Iatroscan system," Journal of Chromatography, vol. 624, no. 1-2, pp. 21-35, 1992.

[2] S. L. Estévez and R. Helleur, "Fatty acid profiling of lipid classes by silica rod TLC-thermally assisted hydrolysis and methylation-GC/MS," Journal of Analytical and Applied Pyrolysis, vol. 74, no. 1-2, pp. 3-10, 2005.

[3] R. Wood, Analysis of Fats, Oils and Lipoproteins, Edited by E.G. Perkins, American Oil Chemists Society, Champaign, Ill, USA, 1991.

[4] B. Freedman, E. H. Pryde, and W. F. Kwolek, "Thin layer chromatography/flame ionization analysis of transesterified vegetable oils," Journal of the American Oil Chemists' Society, vol. 61, no. 7, pp. 1215-1220, 1984. 
[5] J. F. Cavalier, D. Lafont, P. Boullanger et al., "Validation of lipolysis product extraction from aqueous/biological samples, separation and quantification by thin-layer chromatography with flame ionization detection analysis using O-cholesteryl ethylene glycol as a new internal standard," Journal of Chromatography A, vol. 1216, no. 37, pp. 6543-6548, 2009.

[6] V. J. Sinanoglou and S. Miniadis-Meimaroglou, "Fatty acid of neutral and polar lipids of (edible) Mediterranean cephalopods," Food Research International, vol. 31, no. 6-7, pp. 467-473, 1998.

[7] V. J. Sinanoglou and S. Miniadis-Meimaroglou, "Phospholipids in Mediterranean cephalopods," Zeitschrift fur Naturforschung C, vol. 55, no. 3-4, pp. 245-255, 2000.

[8] Food and Drug Administration (FDA), 2001, http://www.fda .gov/downloads/Drugs/GuidanceComplianceRegulatoryInformation/Guidances/ucm070107.pdf.

[9] V. J. Sinanoglou, I. F. Strati, and S. Miniadis-Meimaroglou, "Lipid, fatty acid and carotenoid content of edible egg yolks from avian species: a comparative study," Food Chemistry, vol. 124, no. 3, pp. 971-977, 2011.

[10] V. Loukas, C. Dimizas, V. J. Sinanoglou, and S. MiniadisMeimaroglou, "EPA, DHA, cholesterol and phospholipid content in Pagrus pagrus (cultured and wild), Trachinus draco and Trigla lyra from Mediterranean Sea," Chemistry and Physics of Lipids, vol. 163, no. 3, pp. 292-299, 2010.

[11] K. Tsape, V. J. Sinanoglou, and S. Miniadis-Meimaroglou, "Comparative analysis of the fatty acid and sterol profiles of widely consumed Mediterranean crustacean species," Food Chemistry, vol. 122, no. 1, pp. 292-299, 2010.

[12] T. F. Garofalaki, S. Miniadis-Meimaroglou, and V. J. Sinanoglou, "Main phospholipids and their fatty acid composition in muscle and cephalothorax of the edible Mediterranean crustacean Palinurus vulgaris (spiny lobster)," Chemistry and Physics of Lipids, vol. 140, no. 1-2, pp. 55-65, 2006.

[13] E. D. Dodds, M. R. McCoy, L. D. Rea, and J. M. Kennish, "Gas chromatographic quantification of fatty acid methyl esters: flame ionization detection versus electron impact mass spectrometry," Lipids, vol. 40, no. 4, pp. 419-428, 2005.

[14] N. M. Aini, M. M. Yusoff, and H. A. Azhari, "Chromatographic methods to analyse geometrical and positional isomers of fatty acids. A review," in Proceedings of the National Conference on Postgraduate Research (NCON-PGR '09), UMP Conference Hall, October 2009.

[15] V. J. Sinanoglou, F. Mantis, S. Miniadis-Meimaroglou, G. K. Symeon, and I. A. Bizelis, "Effects of caponisation on lipid and fatty acid composition of intramuscular and abdominal fat of medium-growth broilers," British Poultry Science, vol. 52, no. 3, pp. 310-317, 2011.

[16] V. J. Sinanoglou, S. Athanasiadou, D. Vartholomeos et al., "Quantitation of neutral and polar lipids by Iatroscan TLCFID and of fatty acids by GC analysis in muscles and adipose tissue of lambs and kids," in proceedings of the 6th International Conference of Instrumental Methods of Analysis (IMA '09), Athens, Greece, October 2009.

[17] K. Tsape, V. J. Sinanoglou, and S. Miniadis-Meimaroglou, "Comparative analysis of the fatty acid and sterol profiles of widely consumed Mediterranean crustacean species," Food Chemistry, vol. 122, no. 1, pp. 292-299, 2010.

[18] S. Miniadis-Meimaroglou, L. Kora, and V. J. Sinanoglou, "Isolation and identification of phospholipid molecular species in $\alpha$ wild marine shrimp Penaeus kerathurus muscle and cephalothorax," Chemistry and Physics of Lipids, vol. 152, no. 2, pp. 104-112, 2008.

[19] A. Zervou, V. J. Sinanoglou, G. Papadas, S. N. Thomaidis, and D.-M. Meimaroglou, "Effects of pan-frying on PUFA, MUFA and individual lipid content in Spicara smaris," Acta Alimentaria, vol. 41, no. 1, pp. 33-44, 2012.

[20] P. Zoumpoulakis, V. J. Sinanoglou, A. Batrinou, and I. F. Strati S, "A combined methodology to detect c-irradiated white sesame seeds and evaluate the effects on fat content, physicochemical properties and protein allergenicity," Food Chemistry, vol. 131, pp. 713-721, 2012.

[21] L. M. Papaspyridi, V. J. Sinanoglou, I. F. Strati, P. Katapodis, and P. Christakopoulos, "Fatty acid profiles of Pleurotus ostreatus and Ganoderma australe grown naturally and in a batch bioreactor," Acta Alimentaria. In press. 

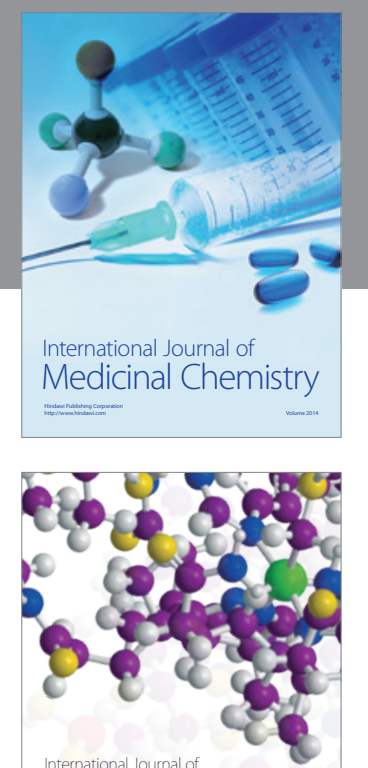

\section{Carbohydrate} Chemistry

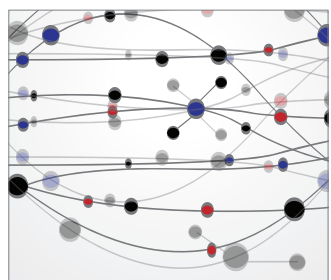

The Scientific World Journal
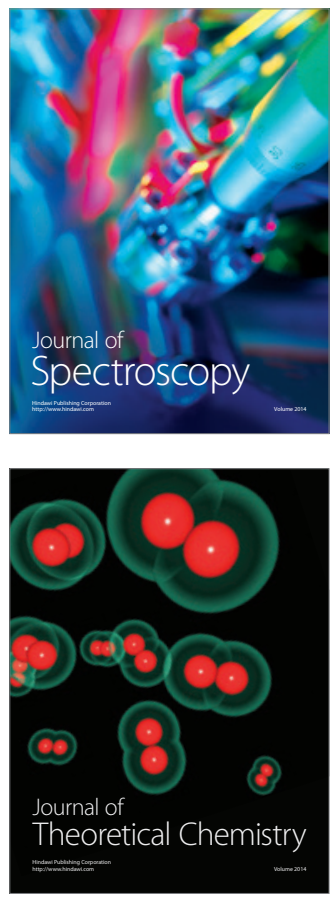
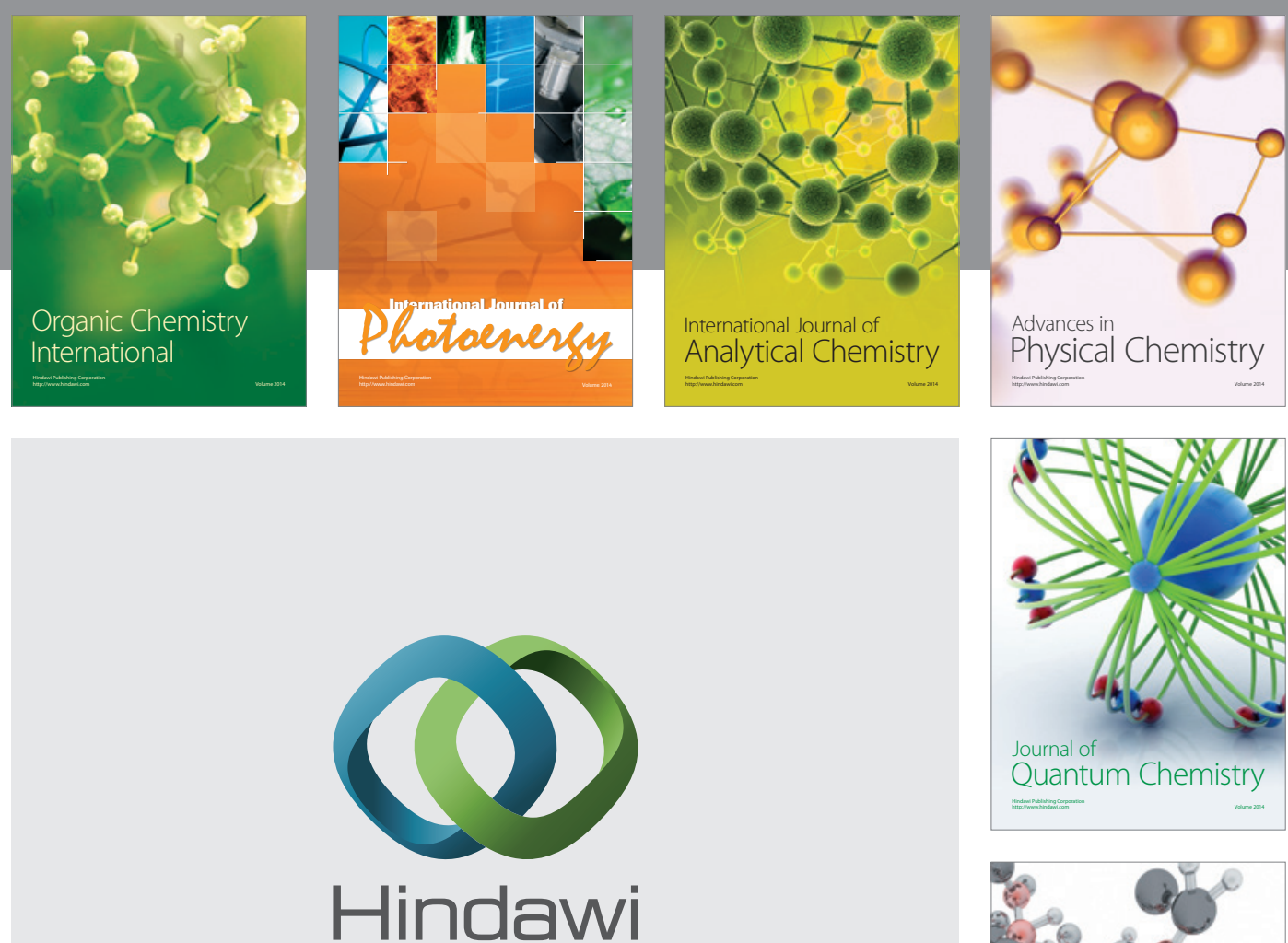

Submit your manuscripts at

http://www.hindawi.com

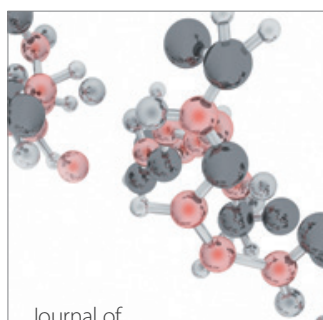

Analytical Methods

in Chemistry

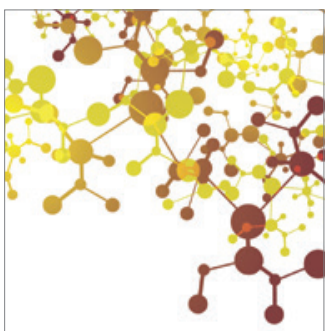

Journal of

Applied Chemistry

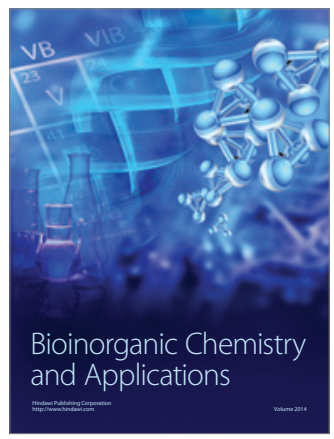

Inorganic Chemistry
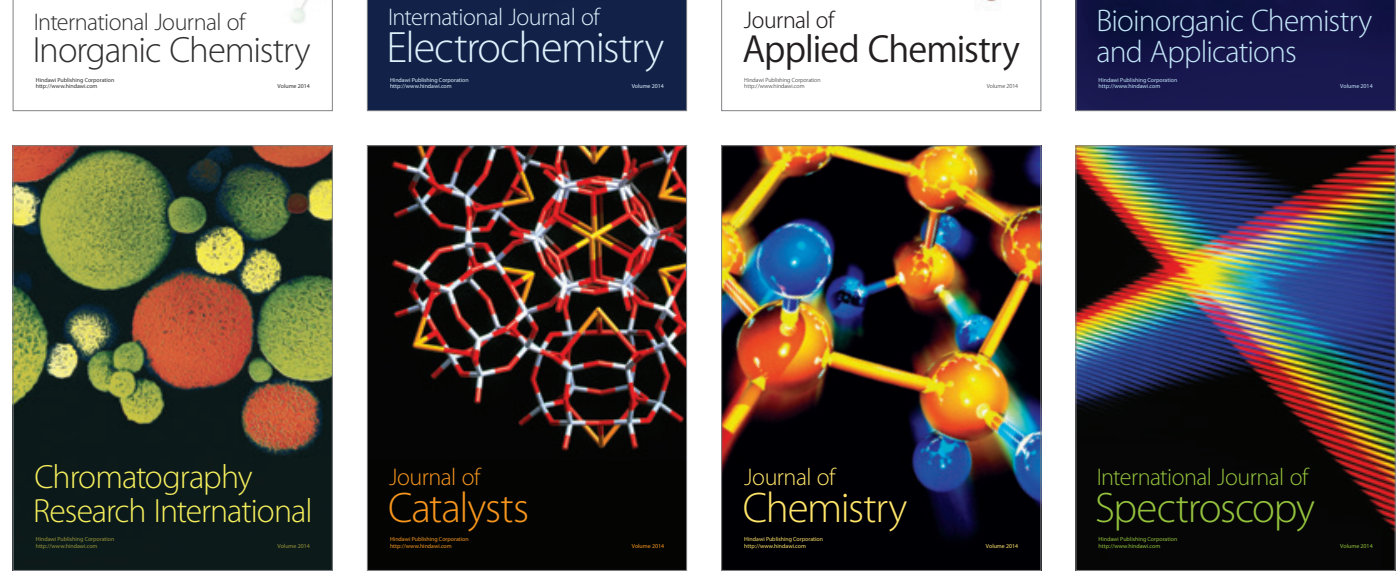